\title{
O ENSINO DE ARTES VISUAIS PARA PESSOAS COM DEFICIÊNCIA VISUAL OU CEGUEIRA
}

\section{ENSEÑAR ARTES VISUALES A PERSONAS CON DISCAPACIDAD VISUALO CEGUERA}

\author{
Marília Cláudia Favreto SINÃNI ${ }^{1}$ \\ Kimberly Weiss CALVES ${ }^{2}$ \\ Paulo Cesar Duarte PAES ${ }^{3}$
}

Resumo: Este artigo visa contribuir com a abordagem no Ensino de Artes Visuais exercido na área de educação especial específica para alunos com deficiência visual e cegueira. No qual o ISMAC - Instituto Sul Mato Grossense para Cegos Florivaldo Vargas localizado em Campo Grande/MS, colaborou como sede para a pesquisa de campo. Como se dá o Ensino de Artes Visuais para alunos que possuem alguma deficiência no campo da visão? Sendo assim, a partir de análises de conteúdos, propomos outras perspectivas para o planejamento das aulas práticas direcionadas a estes alunos, sem que percamos a essência da arte e a importância das referências visuais produzidas ao longo da história. Dentre as problemáticas encontradas em campo, levantamos a evidente presença da prática artística associada a objetos utilitários, por isso adotamos a perspectiva histórico-crítica de Lev Vigotski dentro do ensino da arte, para elucidarmos possíveis alternativas para a valorização do processo de criação dos alunos com deficiência visual na qual a aula de artes visuais torna possível a fruição criadora.

Palavras-chave: Deficiência Visual. Artes Visuais. Expressão. Criatividade. Inclusão.

Resumen: Este artículo tiene como objetivo contribuir al abordaje en la Enseñanza de las Artes Visuales que se ejerce en el área de educación especial especial para estudiantes con discapacidad visual y ceguera. En el cual ISMAC - Instituto Sul Mato Grossense para Ciegos Florivaldo Vargas ubicado en Campo Grande / MS, colaboró como sede de la investigación de campo. ¿Cómo se lleva a cabo la Enseñanza de las Artes Visuales para los estudiantes que tienen una discapacidad en el campo visual? Por ello, a partir del análisis de contenido, proponemos otras perspectivas para la planificación de clases prácticas dirigidas a estos estudiantes, sin perder la esencia del arte y la importancia de los referentes visuales producidos a lo largo de la historia. Entre los problemas encontrados en el campo, se planteó la presencia evidente de la práctica artística asociada a los objetos utilitarios, por eso adoptamos la perspectiva histórico-crítica de Lev Vigotski dentro de la enseñanza del arte, para dilucidar posibles alternativas de valoración del proceso de creación de estudiantes con discapacidad visual en la que la clase de artes visuales hace posible el disfrute creativo.

\footnotetext{
1 Acadêmica de Artes Visuais - Licenciatura pela Universidade Federal do Mato Grosso do Sul. mariliasinarte@gmail.com.

2 Acadêmica de Artes Visuais - Licenciatura pela Universidade Federal do Mato Grosso do Sul. kimweissc@gmail.com.

${ }^{3}$ Docente do curso de Artes Visuais na Universidade Federal do Mato Grosso do Sul. paulo.paes@ufms.br.
} 


\section{MORIZONTES - REVISTA DE EDUCAÇÃO}

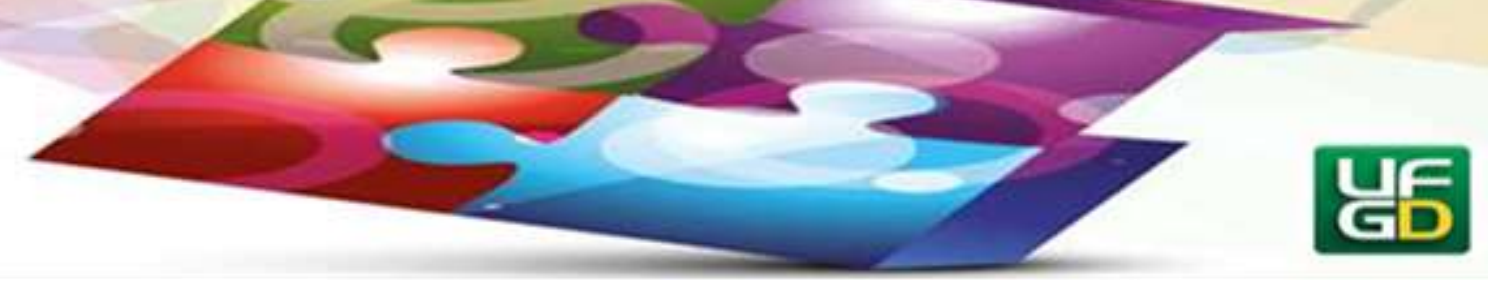

Palabras-clave: Discapacidad visual. Artes visuales. Expresión. Creatividad. Inclusión.

\section{Introdução}

O Ensino de Artes Visuais, quando é exercido na área de educação especial, deve ser adaptado de modo que as condições e necessidades especiais de cada aluno sejam respeitadas, mas esta adaptação é ainda mais dificultada quando o aluno que terá contato com as artes visuais possui deficiência visual ou cegueira. As Artes Visuais, como já se diz em sua nomenclatura, explora de imediato o campo visual do ser humano. $\mathrm{O}$ arte-educador proporciona aos alunos experiências sensíveis e artísticas, lhes apresentando referências visuais a partir da leitura de imagens e apreciação que, mais uma vez, se dá através dos olhos.

Mas como a apreciação e a experiência artística ocorre em alunos com deficiência visual ou cegueira? Neste artigo, analisamos o ensino de Artes Visuais no ISMAC - Instituto Sul Mato Grossense para Cegos Florivaldo Vargas localizado em Campo Grande/MS e, a partir desta análise, elaboramos e propomos conteúdos visando a necessidade de adaptações ao se planejar uma aula prática direcionada a alunos com problemas de visão sem perder a essência da arte e a importância de apresentação das referências visuais produzidas ao longo da história. Com base na análise do ensino de artes visuais na Instituição de Ensino observada, apresentamos a arte como possível e aplicável em sala de aula para os alunos com deficiência visual e cegueira, de modo que sejam abrangidos os outros sentidos, vencendo a hegemonia da visão ${ }^{4}$ no campo das artes visuais, que serão trabalhados a partir de um viés artístico promovendo o desenvolvimento do potencial criativo humano.

\section{O Ensino de Artes Visuais no Instituto Sul Matogrossense para Cegos Florivaldo Vargas}

\footnotetext{
${ }^{4}$ Termo utilizado por Rubem Alves (2011) em Variações sobre o prazer: Santo Agostinho, Nietzsche, Marx e Babette.
} 


\section{MORIZONTES - REVISTA DE EDUCAÇÃO}

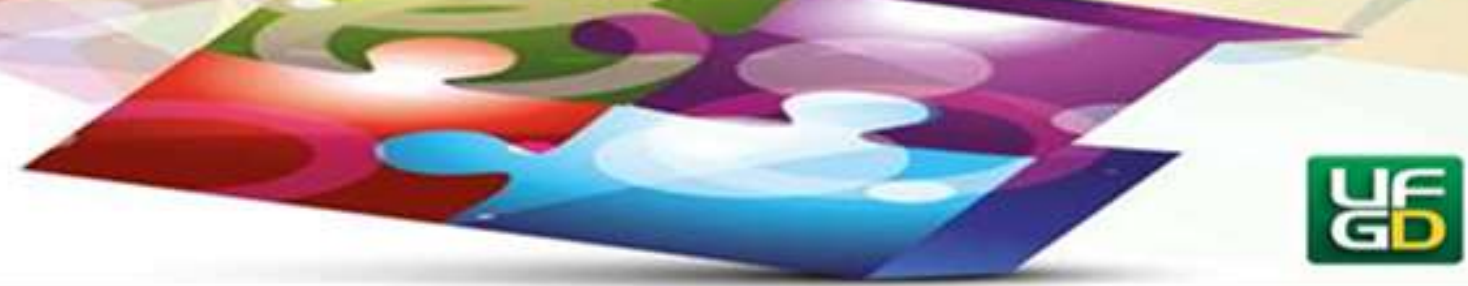

O Instituto Sul Mato Grossense para Cegos Florivaldo Vargas (ISMAC) é o único Instituto responsável pela prestação de serviços, incluindo o ensino do Sistema Braille e Soroban, a pessoas com deficiência visual e cegueira de forma gratuita no Estado do Mato Grosso do Sul. Localizado no centro de Campo Grande, o Instituto tem como alvo todas as pessoas que foram diagnosticadas com deficiência visual ou cegueira por um oftalmologista e que necessitam do atendimento especializado do Instituto que oferece oportunidades essencialmente complementares como suporte para o ensino regular, independentemente da idade dos alunos - faixa etária de 05 a 90 anos - e do perfil socioeconômico dos mesmos, tendo em vista que o ISMAC, atualmente, realiza parceria com a rede do SUS.

O trabalho pedagógico aqui analisado se dá em um Instituto com profissionais de ensino cedidos pelo Estado e pelo Município. O ISMAC necessita de doações, de projetos com parcerias e de convênios com o Município e Estado para garantir a sua existência.

No ISMAC existem alunos com baixa visão e cegueira. Em ambos os casos diagnosticados, existem alunos que nasceram com a cegueira e a baixa visão, mas existem outros que adquiriram devido a algum acontecimento em suas vidas. Antes de iniciar a análise do trabalho realizado pela docente no Instituto, é necessário que se compreenda as definições mencionadas neste artigo que fazem parte da deficiência visual: Cegueira e Baixa Visão.

A Cegueira divide-se em dois tipos: a Cegueira Congênita - ausência de visão durante os primeiros anos de vida devido ao comprometimento do globo ocular que acaba dificultando o desenvolvimento da criança - e a Cegueira Adventícia ou Adquirida - perda de visão de forma repentina por acidentes ou causas orgânicas - mas as pessoas que possuem um desses dois tipos de cegueira não enxergam somente a escuridão, são capazes de perceber vultos, luzes e sombras. (DOMINGUES et al. 2010, p. 30).

De acordo com Domingues et al. (2010, p. 10-14) a Baixa Visão, por sua vez, é uma deficiência visual que pode ser melhorada com a utilização de recursos de acessibilidade como auxílios ópticos que ampliam a imagem e auxílios não-ópticos como manter o ambiente em que estão inseridos sem modificações para não causar confusão com os elementos contidos no espaço. 


\section{MORIZONTES - REVISTA DE EDUCAÇÃO}

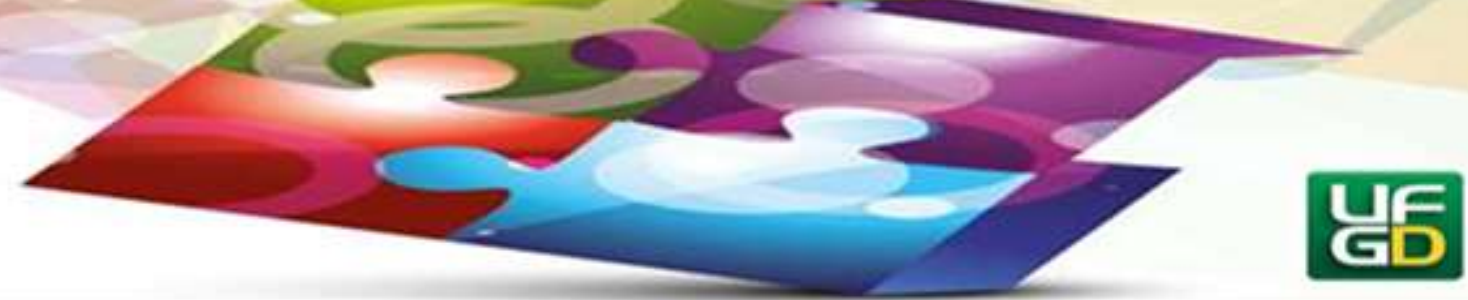

A partir da compreensão das definições de deficiência visual e cegueira, torna-se necessária a análise do ensino de artes visuais de modo que este promova a inclusão e contribua para um desenvolvimento expressivo e criativo destes alunos.

As aulas de arte aqui analisadas são ministradas em uma sala pequena que não comporta muitas pessoas, além de não haver espaço suficiente devido ao excesso de materiais e trabalhos de alunos que tomam conta do ambiente. Apesar deste problema de inadequação do espaço para receber as aulas de arte de modo otimizado, a professora do instituto, embora formada em educação artística com ênfase em Música, atua como professora de Artes Visuais no ISMAC e, constantemente, elabora ideias para adequar as atividades ao espaço, tendo que lidar com a escassez de recursos materiais para as suas aulas, optando por materiais mais acessíveis como materiais recicláveis, papietagem, cerâmica e pinturas em diversos suportes como garrafas que foram descartadas.

A professora produz diversos materiais como alternativa para as suas aulas, criando misturas para produção de papéis e massas parecidas com papel machê, sendo que todos os processos de produção de materiais são realizados em sua residência, o que demonstra a sua maior dedicação profissional aos seus alunos.

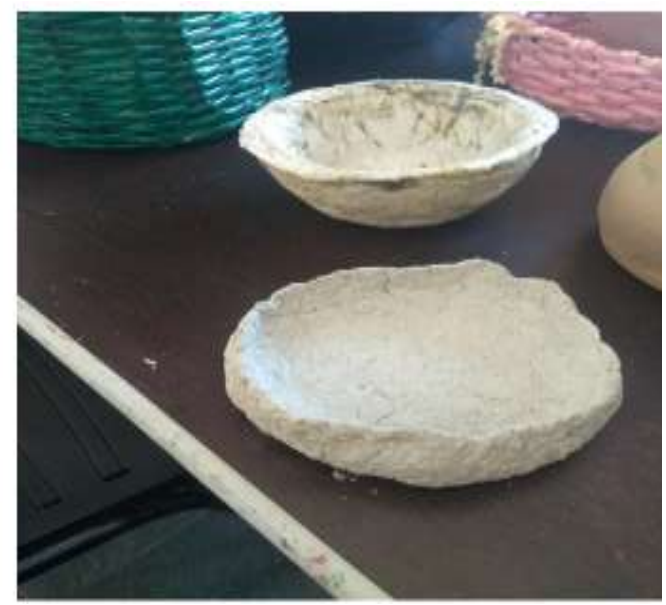

Figura 2: Potes produzidos a partir da massa caseira de papel. Registro fotográfico em: 19 out. 2018.

As atividades elaboradas pela professora, devido aos materiais disponíveis, são mais voltadas para o artesanato como por exemplo, haviam atividades onde os alunos faziam cestos com jornais ou encapavam garrafas de vidro com barbantes, ou seja, tais atividades são voltadas 


\section{HORIZONTES - REVISTA DE EDUCAÇÃO}

para a construção de peças utilitárias tanto em decoração, quanto para utensílios domésticos. Estas atividades são compreensíveis devido à escassez de materiais mais aptos ao desenvolvimento artístico, mas a questão não é a apenas a falta de material, mas a possibilidade de se criar alternativas com o material disponível. As atividades artesanais com materiais recicláveis também são relevantes, porém, o objeto da presente pesquisa e a "arte", que, segundo Lukács (2010), sempre se aprofunda na busca daqueles momentos mais essenciais que se acham ocultos sobre a superfície dos fenômenos, oferecendo um quadro de conjunto da vida humana no seu movimento histórico. Para Vigotski (2001) a arte possibilita uma elevação estética a um patamar sensível mais desenvolvido.

Apesar da importância da arte nestes espaços, em uma das aulas, ocorreu a reprodução de desenhos estereotipados por parte da professora para algumas alunas em uma atividade de pintura em panos de prato onde a professora desenhou flores estereotipadas para uma de suas alunas pintar. De acordo com Vianna (1995) a estereotipação nos desenhos vai contra os princípios estudados para o ensino de Artes Visuais, é algo que empobrece as produções e limita o potencial criador dos indivíduos desde a infância, sendo necessário ser combatido nas aulas de arte através da desestereotipação a partir de exercícios artísticos e estéticos que promovam um outro olhar sobre o mundo e a arte.

Neste caso específico de estereotipação no desenho, a professora acabou reforçando, mesmo que sem intenção, o desenho estereotipado em sua aluna que, mesmo tendo graus de deficiência visual, ainda enxergava as formas e tinha facilidade de apropriação de mundo a partir dos olhos, se estimulada sem a interferência dos estereótipos, a aluna iria de fato estar se expressando e explorando o seu potencial criador.

\footnotetext{
Muitos professores passam horas inteiras preparando desenhos para os alunos pintarem, recortarem, colarem, como presentes para datas comemorativas, por exemplo, Natal ou Páscoa, e, com isso, muitos alunos nunca tiveram a oportunidade de exercitar o seu potencial criador, pois os desenhos estereotipados empobrecem a percepção e a imaginação do aluno, [...] inibem sua necessidade expressiva; embotam seus processos mentais, não permitem que desenvolvam naturalmente suas potencialidades. (VIANNA, 2012, s. p.).
}

Por trabalharem demasiadamente com o artesanato enquanto peça utilitária, os alunos não têm muitas possibilidades de trabalhar com processos criativos com o enfoque na sua 


\section{MORIZONTES - REVISTA DE EDUCAÇÃO}

subjetividade em relação com a totalidade que abrange a necessidade de existência humana que é necessária para o desenvolvimento expressivo e criativo dos alunos, como vemos em:

[...] A obra de arte é um produto de um trabalho peculiar. Esse trabalho produz também um objeto útil que satisfaz uma necessidade humana, a saber, a necessidade de se expressar, afirmar e comunicar que sente o artista imprimindo determinada forma a uma matéria. (VÁSQUEZ, 2011, p. 180).

Os alunos precisam ter a possibilidade de passar por um processo de criação que vai além da construção de peças utilitárias, para vivenciar de fato a arte e se expressar criando por uma necessidade humana de materializar a sua sensibilidade através da técnica, sem um objetivo utilitário já pré-estabelecido.

A valorização do processo de criação dos alunos contribuiria para a apropriação de mundo e para o autoconhecimento dos alunos. Esta apropriação de mundo e do que foi produzido pela humanidade reflete na subjetividade e no processo criador individual de nós, enquanto seres criadores e sociais, sendo explicado por Vigotski (2014, p.12).

A atividade criadora da imaginação está relacionada diretamente com a riqueza e a variedade da experiência acumulada pelo homem, uma vez que essa experiência é a matéria-prima a partir da qual se elaboram as construções da fantasia. Quanto mais rica for a experiência humana, mais abundante será o material disponível para a imaginação.

Apesar de alguns apontamentos, ao ter acesso a recursos materiais de pintura, a professora obteve êxito em seu planejamento, tornando possível que os alunos tivessem a oportunidade de pintar além de algo utilizado para decoração, pintando o que sentiam diante do mundo e de suas vivências particulares.

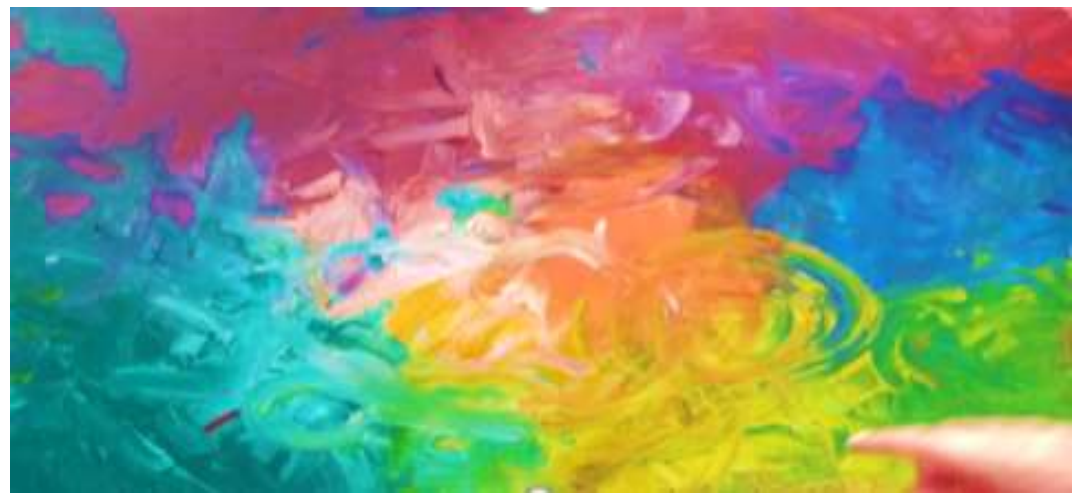




\section{MORIZONTES - REVISTA DE EDUCAÇÃO}

Figura 2: Pintura realizada por uma aluna de 32 anos com deficiência visual que descreve um aborto. Registro fotográfico em: 19 out. 2018 .

Observe que na Figura 2 acima, a aluna do ISMAC teve acesso a pintura em tela, material da qual não possui tanto acesso, mas que oferece inúmeras possibilidades técnicas e expressivas se forem mediadas de forma correta. Neste caso, a professora distribuiu as telas e propôs uma atividade que relatasse o cotidiano dos alunos, sem interferências no processo criativo e no trabalho dos mesmos, deixando-os experimentar os materiais e encontrarem soluções próprias para organizar as suas composições. Ao questionar a professora que nos apresentava o trabalho retratado na Figura 1, a mesma ressaltou que durante o seu processo criativo, a aluna explicou que o seu trabalho artístico se tratava da dor que sentiu ao sofrer um aborto há alguns anos atrás. Por trás de seu trabalho artístico, estava toda a sua individualidade estritamente expressa e pensada durante o seu processo criativo. Percebe-se que a aluna explorou a sua subjetividade considerando a sua vivência e expressou-se de modo abstrato com um intuito que ia muito além da produção de um utensílio, tratava-se da utilização da arte como um instrumento de descarga emocional.

É necessário compreender que a aluna ter passado por um processo criativo e subjetivo não dependeu apenas do material, mas sim de como a proposta da atividade foi realizada e as técnicas ensinadas para que este processo criativo e a pintura, enquanto produto de tal processo, fossem capazes de existir. Quando Fischer (1976, p. 14) discorre sobre o trabalho do artista como um trabalho consciente e racional, podemos também associar tal definição ao Ensino de Artes Visuais, quando o autor afirma que antes de um trabalho final, passa-se por um processo onde apenas a emoção não basta para dar uma forma a matéria, é necessário saber utilizar as técnicas e recursos para chegar a um resultado final. Ou seja, não é apenas considerar a emoção do indivíduo no processo criativo, é necessário dar condições, através do ensino, para que ele consiga encontrar soluções para materializar o que sente.

Independente do material, é necessário que se saiba propor uma atividade que englobe todos os alunos e que os mesmos consigam compreendê-la para um possível desenvolvimento. $\mathrm{Na}$ aula de artes do ensino regular, por exemplo, a maior parte dos alunos possuem a visão para compreender a arte, sendo os alunos com deficiência visual uma minoria que, muitas vezes, são 


\section{HORIZONTES - REVISTA DE EDUCAÇÃO}

deixados de lado realizando uma outra atividade, resultando em uma falsa inclusão. Enquanto na aula de artes do ISMAC, devido ao fato de todos os alunos terem graus de deficiência visual, apesar de ainda ser algo difícil, o ensino de artes visuais passa a ser mais produtivo porque há todo um cuidado e preparo em incentivá-los a se tornarem mais independentes.

Os únicos problemas percebidos foram a falta de infraestrutura para a aula de artes e o artesanato enquanto peça utilitária sem muito incentivo da expressão subjetiva e do potencial criador dos alunos. Um outro ponto a ser analisado é a ausência de referências visuais, mesmo que ditas verbalmente, apresentadas aos alunos, dificultando a leitura de imagens descritiva e a apreensão da história da arte.

Por isso, propomos neste artigo atividades que tornam possível o ensino de Artes Visuais para alunos com deficiência visual, buscando não restringir os mesmos a apenas um sentido (visão), buscando romper com o "vício da ocularidade"5 e incentivá-los a perceber que é possível adquirir saberes através dos seus outros sentidos, considerando os dizeres de Bachelard em Alves (2011, p. 62) "É bem sabido que os saberes derivam-se da visão." Bachelard nota que, desde os antigos gregos, o pensar é sempre entendido como uma extensão da óptica, a visão exercendo forte hegemonia sobre os demais sentidos.

A hegemonia exercida pela visão acaba por diminuir a importância dos demais sentidos desde o início dos tempos. Conforme Alves (2011), os saberes são conhecimentos científicos que se dão através dos olhos desde a elaboração da palavra "teoria" que, no grego, tem como significado "contemplar", relacionando o saber com apenas a visão. Esta noção de que "saber é ver" acaba limitando o processo de desenvolvimento dos alunos com deficiência visual que acabam acreditando ser impossibilitados de aprender devido à falta de visão e cabe a nós educadores desmitificarmos esta crença global através de atividades bem elaboradas.

Considerando que os alunos do ISMAC possuem maior acesso ao artesanato que se tornou o conteúdo mais próximo dos alunos, trabalharemos com a Arte Popular nesta possível elaboração de atividade artística. Primeiramente, é necessário que os alunos tenham acesso a

\footnotetext{
${ }^{5}$ Termo utilizado por Bachelard afirmando-o ser uma ditadura da visão e por Nietzsche que denuncia o mesmo termo devido ao fato de limitar as formas de se conhecer o mundo através de outros sentidos. Disponível em: ALVES, Rubem. Variações sobre o prazer: Santo Agostinho, Nietzsche, Marx e Babette. São Paulo: Editora Planeta do Brasil, 2011.
} 


\section{MORIZONTES - REVISTA DE EDUCAÇÃO}

um conteúdo teórico para que entendam o porquê da realização de uma atividade prática. Nesta aula expositiva, é recomendável que a professora utilize como base o livro "O Brasil na Visão do Artista: o país e sua cultura" do autor Frederico de Morais (2003) que realiza estudos sobre a Arte Popular e a Cultura Brasileira, e explique o que é a Arte Popular e os seus temas e o quanto ela tem se tornado marginalizada diante da Arte Erudita, ressaltando que a Arte Popular é extremamente importante porque resgata a herança cultural priorizando o povo, sendo uma arte feita pelo povo e para o povo. Tal explicação deve ser elaborada para que o aluno imagine tanto as situações em que teve contato com a Arte Popular (MORAIS, 2003), quanto às descrições do conteúdo explicado pela professora.

Para uma melhor compreensão dos alunos, é necessário que se leve obras de artistas populares regionais adaptando-as, por exemplo: em uma imagem impressa da obra, pode-se colar barbantes em volta da forma dos objetos contidos na obra, para que, através do tato, os alunos possam sentir a obra com os dedos que contornam os personagens ali contidos. Dado o conteúdo, os alunos terão espaço para falar sobre como foi a sensação do contato com a obra e em seguida, a professora poderá apresentar como proposta prática aos alunos a elaboração de um desenho com barbantes em uma superfície bidimensional que se tratem sobre como é morar no Mato Grosso do Sul e quais são as características que eles mais se identificam no Estado. Nesta atividade, os alunos teriam a possibilidade de adentrar em um processo criativo individual através do tato, além de perceberem que é possível desenhar com outros materiais sem se limitarem apenas ao lápis, sendo possível trabalhar um dos itens propostos no Referencial Curricular do Estado que se trata da arte regional.

Existem inúmeras possibilidades para se trabalhar Artes Visuais com alunos com deficiência visual. Ainda é possível trabalhar a sinestesia e a abstração com os alunos, utilizando músicas, a corporalidade, drama, entre tantas outras formas para que os mesmos se expressem através das sensações obtidas pela audição e do contato com a tinta, ou pode-se trabalhar o paladar elaborando um prato em forma de pintura ou escultura e depois, devorando-o em grupo poderão trocar experiências sensitivas sobre a sensação obtida enquanto apreciadores e enquanto criadores das produções artísticas. 


\section{HORIZONTES - REVISTA DE EDUCAÇÃO}

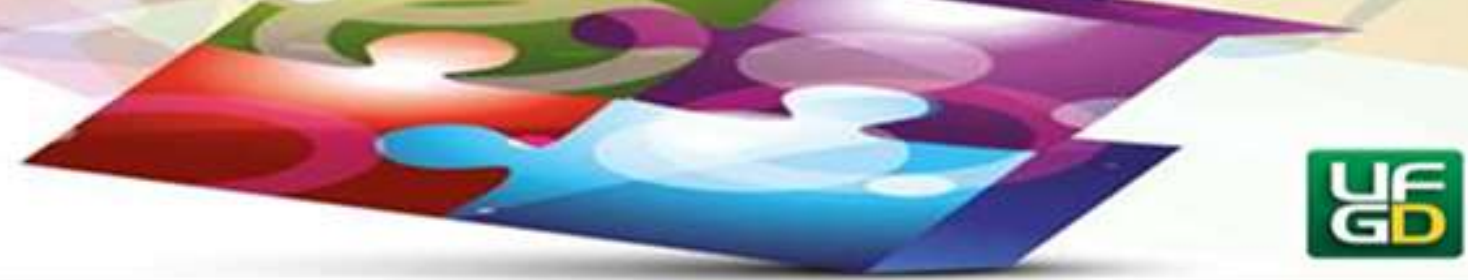

Todos os alunos com deficiência visual possuem a capacidade de se desenvolver a partir da vivência nas Artes Visuais, basta terem acesso a uma aula que torne possível a fruição da arte, a compreensão e a apropriação das referências da história da arte de modo que contemple e considere os seus processos criativos sem limitá-los à diminuição de seus potenciais criadores devido à falta de visão.

\section{Considerações finais}

O ensino de Artes no ISMAC é dado com respeito e dedicação por parte da educadora, mas ainda há a necessidade de incentivos para que os alunos adentrem processos subjetivos e individuais ao elaborarem um trabalho e que não se limitem apenas a peças utilitárias e desenhos estereotipados. É necessário que os mesmos possam ter maior liberdade de produção artística e vivência estética através dos demais sentidos, já que constantemente são limitados pelo "vício da ocularidade" que os impedem de se desenvolverem artisticamente.

Como vimos neste artigo, é possível que os alunos trabalhem com as Artes Visuais através de seus outros sentidos, sem se limitarem apenas ao campo visual, mas é necessária uma maior elaboração de atividades por parte dos educadores que deverão se livrar de possíveis préconceitos acerca do potencial criador dos alunos, deixando-os se expressarem sem interferências, atuando apenas como mediadores das atividades. Esta reelaboração das aulas poderá acarretar em uma maior autonomia artística dos alunos que irão além das suas limitações físicas e ainda acrescentarão na formação dos educadores que, apesar de muitas vezes adentrarem a educação especial sem o preparo específico que deveria ser promovido por uma formação continuada, terão acesso a novas possibilidades de trabalho e crescimento profissional.

Não importa o material que será utilizado ou a falta dele, o que garante o desenvolvimento do aluno com deficiência visual nas Artes Visuais é a forma como o educador elabora propostas que se adequem aos materiais que serão utilizados nas atividades práticas em suas aulas. O papel do professor de Artes Visuais é proporcionar atividades onde o aluno possa ter experimentações artísticas, mesmo que essas não se deem através da visão, mas sim de outros sentidos. O saber não se limita apenas ao campo visual, o saber é acessível de diversas 


\section{HORIZONTES - REVISTA DE EDUCAÇÃO}

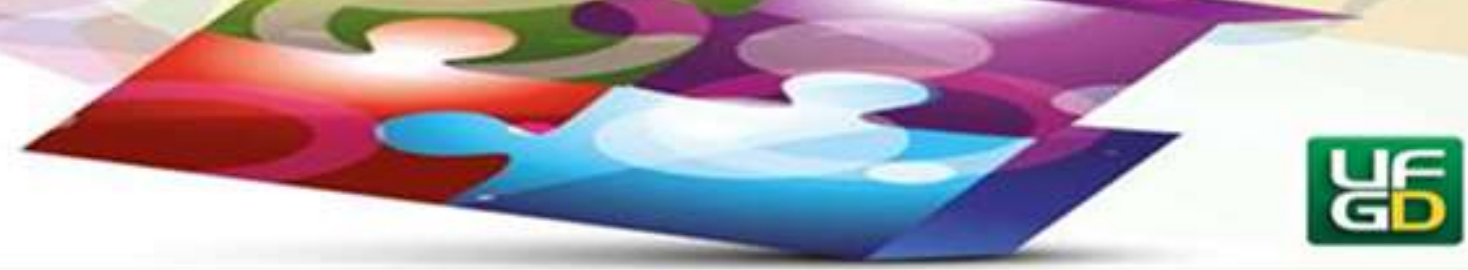

formas e todos os alunos com deficiência visual devem ter acesso às Artes Visuais porque os mesmos possuem sensibilidade e potencial criador a ser explorado.

\section{Referências}

ALVES, Rubem. Variações sobre o prazer: Santo Agostinho, Nietzsche, Marx e Babette. São Paulo: Editora Planeta do Brasil, 2011.

DOMINGUES, C. A. et al. Os alunos com deficiência visual: baixa visão e cegueira. Brasília: MEC, 2010.

FISCHER. Ernst. A função da arte. In: A Necessidade da Arte. Trad. Leandro Konder. Rio de Janeiro: Zahar Editores, 1976.

LUKÁCS, G. Cultura Arte e Literatura: textos escolhidos de Karl Mark e Friedrich Engels. São Paulo. Expressão Popular, 2010.

MORAIS, Frederico. Arte popular: questão social. In: O Brasil na visão do artista: 0 país e sua cultura. São Paulo: Sudameris, 2003. p.80-95.

VÁZQUEZ. Adolfo S. As ideias estéticas de Marx. São Paulo: Ed. Expressão popular, 2011.

VIANNA, Maria Letícia Rauen. Desenhos estereotipados: um mal necessário ou é necessário acabar com este mal? 3 dez. 2012. Disponível em:< http://artenaescola.org.br/sala-deleitura/artigos/artigo.php?id=69343> . Acesso: 18 nov. 2018.

VIGOTSKI, L. S. Psicologia da Arte. São Paulo: Martins Fontes, 2001.

VIGOTSKI. L. S. Imaginação e Criatividade na Infância. São Paulo: Editora WMF Martins Fontes. 2014. P. 9-24.

Enviado: 30/06/2020

Aceito: $31 / 08 / 2020$ 